\title{
KAFALA Y ADOPCIÓN. EL AUTO DE LA AUDIENCIA PROVINCIAL DE BARCELONA (SECCIÓN 18) NÚM. 220/2020 DE 10 DE JUNIO
}

\author{
KAFALA AND ADOPTION. THE RESOLUTION \\ OF THE PROVINCIAL COURT OF BARCELONA (SECTION 18) \\ NUMBER 220/2020 10 JUNE
}

\author{
SALOMÉ AdRoHER Biosca \\ Profesora propia ordinaria de Derecho internacional privado \\ Universidad Pontificia Comillas
}

Recibido: 07.11.2020 / Aceptado: 24.11.2020

DOI: https://doi.org/10.20318/cdt.2021.5981

\begin{abstract}
Resumen: La constitución de una adopción en España tras una kafala en origen, prohibida por el artículo 19.4 de la LAI, ya no se plantea por familias españolas como alternativa a la adopción internacional, sino por familias musulmanas de origen extranjero residentes en España probablemente para superar algunas barreras del Derecho de extranjería. El Auto de la AP de Barcelona recuerda que tal prohibición no vulnera el CEDH y que su aplicación no contradice el orden público español, desde la perspectiva del interés superior del niño, toda vez que su protección familiar está garantizada a través de la kafala. Sin embargo, el caso pone de relieve que la legislación de extranjería en la materia debe garantizar el derecho a vivir en familia, contenido esencial del interés superior del niño, en línea con lo apuntado por el TJUE en la sentencia de 26 de marzo de 2019.
\end{abstract}

Palabras clave: kafala, adopción, Derecho de extranjería.

Abstract: Adopting a child in Spain after a kafalah in his country of origin, is forbidden under spanish law since 2015, as in other european countries. Nowadays, some muslim migrant families try to adopt to avoid some immigration barriers. The case shows that the prohibition is consistent with the best interest of the child, already protected by the kafalah, but also that immigration laws must guaranty his right to a effective family life.

Keywords: kafala, adoption, immigration rules.

Sumario: : I. Antecedentes de hecho y resolución judicial. 1. La Kafala como medida de protección del niño. 2. La Kafala en Derecho internacional privado español. III. La Kafala en el Derecho de extranjería. IV. Consideraciones finales.

\section{Antecedentes de hecho y resolución judicial}

1. Dos marroquíes residentes en España que contrajeron matrimonio en 1995, constituyeron en 2016 en Tánger una kafala judicial de un niño de padres desconocidos. Se les nombró tutores dativos, pero no se autorizó el desplazamiento del menor a España, ni que fijara en nuestro país su residencia permanente. En esa fecha el marido ya había adquirido la nacionalidad española. En junio de 2019 pre-

*s.adroher@comillas.edu 
sentaron en España su ofrecimiento para adoptar al niño. En primera instancia se inadmitió a trámite la demanda porque el Juzgado entendió que los adoptantes debían tener un certificado de idoneidad. La Audiencia Provincial (AP) de Barcelona en su Auto de 10 de junio de $2020^{1}$ desestima el recurso de apelación pero por una razón distinta: la prohibición de constituir una adopción tras una kafala prevista en el art. 19.4 de la Ley 54/2007 de adopción internacional (LAI)2 ${ }^{2}$. Se trata de una importante y muy bien fundamentada resolución judicial que, sin embargo, pone de relieve en qué medida las disposiciones de Derecho privado y de Derecho de extranjería actúan como vasos comunicantes.

\section{Cuestiones de Derecho internacional privado}

2. El presente Auto es una de las numerosas resoluciones judiciales, que, en los últimos años, abordan los efectos de las kafalas islámicas en España, tanto desde la perspectiva del Derecho privado e internacional privado ${ }^{3}$, como desde la del Derecho de extranjería ${ }^{4}$. He tratado en dos trabajos anteriores ${ }^{5}$ esta singular institución que, como respuesta a la prohibición coránica de la adopción prevista en gran parte de los países islámicos, con excepciones ${ }^{6}$, comporta una medida de protección de menores reconocida en diversos convenios internacionales 7 . En virtud de ella, una mujer o un matrimonio musulmán se hace cargo de un menor, comprometiéndose a cuidarle, educarle y protegerle "como un padre lo haría con su hijo", e instruirle en la fe islámica, pero sin que se establezcan entre ellos vínculos paterno-filiales ${ }^{8}$.

\section{La kafala como medida de protección del niño}

3. En el Derecho de los países islámicos, como es el caso de Marruecos ${ }^{9}$ o Argelia, países con estrechas relaciones jurídicas con España, existen dos tipos de kafalas: judiciales y notariales. Las judiciales se constituyen a favor de niños huérfanos, o de padres desconocidos; la autoridad judicial identifica a los niños beneficiarios (makfoules), elige la familia de acogida (kafiles), y establece el ejercicio y seguimiento de la medida" ${ }^{10}$. La kafala otorga la "tutela dativa" al kafil, se inscribe en el Registro civil

${ }^{1}$ ECLI: ES:APB:2020:4271

${ }^{2}$ BOE 29 de diciembre de 1997.

${ }^{3}$ Autos de la AP de León de 27 de junio de 2019 (ECLI:ES: APLE: 2019: 922ª), AP de Barcelona de 28 de mayo de 2019 (ECLI: ECLI:ES: APB:2019:3237A), AP de Alicante de 16 de octubre de 2019 (ECLI:ES:APA:2019:4024), AP de Valencia de 5 de mayo de 2020 (ECLI: ES: APV:2020:1104A), AP de Barcelona de 11 de junio de 2020 (ECLI: ES:APB:2020:4370).

${ }^{4}$ Sentencias del TSJ de Andalucía de 23 de mayo de 2019 (ECLI:ES: TSJAND: 2019:7460), y de Madrid de 11 de abril de 2019 (ECLI:ES: TSJM:2019:7749) y de 31 de mayo de 2019 (ECLI:ES: TSJM:2019:8516 ).

${ }^{5}$ S. Adroher Biosca. «Un estudio de caso sobre adoptabilidad: la kafala islámica». En B. Gómez Bengoechea, A. Berástegui Pedro-Viejo, S. Adroher Biosca. Se busca familia para un niño. Perspectivas psico-juridicas sobre la adoptabilidad. Madrid, Dykinson, Comillas. 2015; S. AdroHer BioscA. "La kafala islámica: ¿medida de protección de menores o estrategia migratoria? Revista de Derecho migratorio y de extranjería no 45, 2017, pp. 203-20.

${ }^{6}$ K. ouad ali, t. Saguir, “Acercamiento a la adopción en los países del Magreb”. En G. Esteban de la Rosa, g. (Dir) Regulación de la adopción internacional. Nuevos problemas, nuevas soluciones, Navarra, Thomson Reuters Aranzadi, 2007 , p. 87.

${ }^{7}$ Artículo 20 de la Convención de Naciones Unidas de Derechos del Niño de 1989, y artículo 3 del Convenio relativo a la competencia, la ley aplicable, el reconocimiento, la ejecución y la cooperación en materia de responsabilidad parental y de medidas de protección de los niños, hecho en La Haya el 19 de octubre de 1996, (BOE 2 de diciembre de 2010, CH96).

${ }^{8}$ A. RodrigueZ Benot. "Adopción y kafala: un análisis de su alcance respectivo en los ordenamientos islámicos y occidentales”. Derecho internacional y relaciones internacionales en el mundo mediterráneo, 1999, pp. 195-208; P. Diago Diago. La kafala islámica en España. CDT, vol. 2, nº 1, marzo 2010, p. 142; N. MARChAL Escalona. "La kafala islámica: problemática y efectos”. En F. J. Duran Ruiz, (Dir.) Actas del I Congreso internacional retos sociales y jurídicos para los menores y jóvenes del Siglo XXI. Granada, Comares 2013, pp. 237-270.

${ }^{9}$ H. Zekri, J. Ouhida "La kafala en el Derecho marroquí", en A. QuiÑones esCÁmez, A. rodrígueZ Benot, H. Zekri, J. OuhidA. Kafala y adopción en las relaciones hispano-marroquies. FIIAPP, Madrid, 2009, pp. 15-130.

${ }^{10}$ A. SAHLi, F. Ezzahzi "El interés superior del niño en la jurisprudencia marroquí" en El Interés superior del niño en la jurisprudencia internacional y comparada., S. SAnz Caballero, N.M. Molina NaVArro, Dirs.). Navarra, Thomson Reuters Aranzadi, CEU, CEDRI y MINECo 2017, p. 187. 
y tiene algunos efectos coincidentes con los de la filiación biológica ${ }^{11}$. El más relevante para el tema que nos ocupa, es la representación legal, que, si bien no siempre ha sido reconocida en España ${ }^{12}$, se ha afirmado indubitadamente por la Fiscalía General del Estado (FGE) ${ }^{13}$.

4. En las kafalas notariales, son los padres del niño quienes, mediante un acta adular, "asignan" el cuidado de su hijo a un kafil, normalmente de su círculo familiar, sin transferirle la representación legal, sino, simplemente, la guarda. Con frecuencia se ha utilizado por las familias migrantes: el niño se envía a vivir con unos parientes residentes legales en Europa, aliviando así a los padres de su manutención, permitiendo a los hijos el acceso a mejores recursos educativos y sanitarios y a los kafiles beneficiarse de su compañía, si bien en ocasiones se han denunciado situaciones de explotación laboral infantil en estos $\operatorname{casos}^{14}$. Las kafalas notariales pueden homologarse judicialmente, pero, mientras la homologación en Marruecos es una mera "autenticación", en Argelia transforma la kafala en judicial ${ }^{15}$.

\section{La kafala en Derecho internacional privado español}

5. Es frecuente, como en el Auto analizado, que los kafiles que constituyen kafalas en países islámicos, residan en el extranjero y pretendan desplazar al makfoul a su país de residencia ${ }^{16}$. Desde la perspectiva del Derecho privado, cuatro cuestiones son relevantes: su no reconocimiento como adopción, su reconocimiento como medida de protección, la prohibición de transformarla en adopción, y su posible transformación en tutela o acogimiento familiar en España ${ }^{17}$.

6. Las legislaciones de los países europeos niegan el reconocimiento de la kafala como una adopción. El Convenio de La Haya relativo a la protección del niño y a la cooperación en materia de adopción internacional de 1993 (en adelante CH93) ${ }^{18}$, excluye las kafalas de su ámbito de aplicación, y la legislación española exige, para reconocer en España una adopción constituida en el extranjero, que exista equivalencia sustancial en el contenido de la "adopción extranjera" con la regulada en nuestro Derecho, equivalencia que no se da en las kafalas ${ }^{19}$.

7. Sin embargo, la LAI, en consonancia con el CH96, prevé la producción de efectos en España de las kafalas y otras medidas de protección de menores adoptadas en el extranjero, siempre que reúnan determinados requisitos. En su artículo 34 regula un reconocimiento incidental registral, que, sin embargo, no impedirá, a las partes, si lo desean, acudir a un procedimiento de exequatur ${ }^{20}$. Los kafiles

\footnotetext{
${ }^{11}$ Guarda y custodia, obligación de alimentos, administración de sus bienes, derecho a las ayudas económicas previstas para las familias con hijos y la responsabilidad civil. Además, en algunos casos se permiten hacer legados a favor de menor e incluso otorgarle los apellidos del kafil, como sucede en el caso del Auto comentado.

${ }^{12}$ Resolución DGRN núm. 62/2015 de 12 junio. (JUR 2016\40928) en la que se niega este efecto respecto de unos kafiles que como representantes legales del makfoul, solicitaban en su nombre la nacionalidad española por residencia. Como precedente, Resolución DGRN núm. 91/2013 de 4 noviembre. (JUR 2014\1996).

${ }^{13}$ Circular 8/2011, de 16 de noviembre de 2011, de la FGE (JUR 2011\395482) y Dictamen 3/2016 del FGE.

${ }^{14}$ SAVE THE CHILDREN (2008), Esclavos puertas adentro: Las peores formas de trabajo infantil doméstico, Madrid.

${ }^{15}$ Un exhaustivo análisis de ambas se realiza en una circular del Ministerio de Justicia francés: Circulaire du 22 octobre 2014 relative aux effets juridiques du recueil légal en France. (NOR: JUSC1416688C; BOMJ n²014-11 du 28 novembre 2014 - JUSC1416688C).

${ }^{16}$ Z. COMBalía, M.P. DiAgo diago, M. GonZÁlez varas, Derecho islámico e interculturalidad, Madrid: Iustel, Madrid 2011, pp. 11-159. International Social Service, Centro Internacional de Referencia para los Derechos del Niño Privado de Familia, Ficha de formación $\mathrm{n}^{\mathrm{o}} 51$. http://www.iss-ssi.org.

${ }^{17}$ N. Marchal Escalona. "Problèmes actuels de reconnaissance de la kafala marocaine auprès des autorités espagnoles. Paix et Securité Internationales. No 4, janvier-décembre 2016, pp. 197-230

${ }^{18}$ BOE de 1 de agosto de 1995.

${ }^{19}$ Artículo 26.2. de la LAI.

${ }^{20}$ Art. 26.1. del CH96, art. 41.2 de la Ley de cooperación jurídica internacional en materia civil (LCJIMC-BOE de 31 de julio de 2015) y art. 11 de la Ley de jurisdicción voluntaria (BOE de 3 de julio de 2015). La jurisprudencia ha admitido en ocasiones el reconocimiento incidental (Auto de la AP de Sevilla, Sección 2a de 16 enero 2007 (JUR\2007\178227)), o por exequátur (Sentencia núm. 643/2016 de 2 septiembre del TSJ de Madrid, JUR 20161241572).
} 
promoverán una anotación en el Registro Civil español de la kafala, y el Juez encargado verificará si la kafala se ajusta a lo previsto en el CH96 o en la LAI, operando así su "reconocimiento incidental", verificación cuyo alcance depende de que el niño provenga de un Estado parte en el CH96 (como Marruecos) en cuyo caso el art. 23 CH96 prevé un reconocimiento "de pleno derecho", pero también unas causas de denegación del mismo, o que el niño provenga de un Estado no parte, en cuyo caso se aplicarán las condiciones previstas en el art. 34 de la LAI. Una vez reconocida, y aunque se anote en el RC como acogimiento o tutela, desplegará en España los efectos previstos en el ordenamiento marroquí, tal y como establece el art. 44.4 de la LCJIMC ${ }^{21}$.

8. La tercera cuestión a analizar es, precisamente, a la que se refiere el Auto, y otros anteriores en el mismo sentido ${ }^{22}$, a diferencia de otros ${ }^{23}$ : la prohibición de constituir una adopción en España tras la kafala en el país de origen, prohibición que se contempla también en la legislación de diversos países europeos $^{24}$, y que, según el TEDH, no constituye una injerencia en la vida familiar ${ }^{25}$. Ya he expuesto en los otros trabajos citados, cómo la kafala se utilizó en el pasado por familias europeas, y españolas como alternativa a la adopción internacional ${ }^{26}$ y cómo el Gobierno de Marruecos cerró las kafalas a los extranjeros que no residían en ese país, para evitar que, por esta vía pudiera "burlarse" la prohibición islámica de la adopción ${ }^{27}$. La prohibición se justifica en que si se constituye una adopción tras una kafala, la adopción es "claudicante", toda vez que no es válida en el país de origen del niño y por tanto puede comprometer su seguridad jurídica ${ }^{28}$. Además, las kafalas no se llevan a cabo con los estándares del CH93 ya que la determinación de idoneidad de los adoptantes, la adoptabilidad del niño y sobre todo la asignación, siguen cauces alternativos a los del procedimiento administrativo general de la adopción internacional. Finalmente, la utilización de la kafala para proceder posteriormente a una adopción puede suponer, en algunos casos, un fraude a las normas del país de origen, que exigen para dar a un menor en kafala la profesión de fe islámica de quienes le acogen, y la residencia en ese país.

9. El proyecto de ley de LAI en 2007 previó por primera vez en Derecho español esta prohibición, que, sin embargo, desapareció del texto final debido a las enmiendas presentadas y aceptadas en el Con-

\footnotetext{
${ }^{21}$ La sentencia de la AP de Alicante de 16 de octubre de 2019 ya citada, sin embargo, ante un divorcio de dos kafiles, niega equivocadamente el derecho de alimentos del makfoul: "esta institución jurídica marroquí, no tiene una correspondencia en nuestro derecho con los vínculos de filiación que regula el artículo $91 \mathrm{CC}$ y que a través del divorcio pretendido puede conllevar la constitución de una serie de medidas reguladoras de las relaciones paterno filiales y económicas pretendidas por la parte, ni como alimentos no tampoco como cargas del matrimonio".

${ }^{22}$ Autos de la AP de Barcelona núm. 235/2019 de 28 mayo, de la AP de Valencia de 5 de mayo de 2020 núm. 57/2019 de 27 junio de la AP de León, ya citados.

${ }^{23}$ Autos citados críticamente por el que comentamos, y por M. GUZMÁn ZAPATER. "Kafala y Derecho español tras la reforma de la Ley 54/2007. A propósito del Auto AP de León de 27 de junio de 2019. CDT (Octubre 2020), Vol. 12, No 2, p. 1042: Islas Baleares de 25 de octubre de 2017 y Girona de 18 de diciembre de 2017.

${ }^{24}$ Así lo recoge la Sentencia Harroudj c. Francia de 4 de octubre de 2012 del TEDH (REC 43631/2009): "Dans certains de ces Etats (Finlande, Suisse, Danemark, Suède, Belgique), la législation ou la pratique internes expriment une certaine réticence face à l'adoption d'enfants en provenance de pays interdisant l'adoption - par exemple, en imposant des conditions supplémentaires dans une telle hypothèse».

${ }^{25}$ Chbihi Loudoudi y otros contra Bélgica. Sentencia de 16 diciembre 2014. (TEDH 2014\101).

${ }^{26}$ Así se pone de manifiesto en diversas resoluciones judiciales y administrativas: Auto de la AP de Santander de 30 de abril de 2015(JUR 2015 \275325), Sentencia de la AP de Valladolid de 12 de abril de 2013 (JUR 2013\182397), Sentencia de la AP de Málaga de 31 de junio de 2016, (JUR 2016 267412) y Resolución DGRN núm. 28/2016 de 29 enero. (JUR 20161217954).

${ }^{27}$ Circular $n^{\circ} 40 \mathrm{~S} / 2$ del Ministro de Justicia y de las libertades marroquí de julio de 2012. Un comentario a la misma de P. Diago Diago http://www.millenniumdipr.com/e-68-5-n\%C2\%-

${ }^{28}$ El caso resuelto por el Auto de la AP de Valencia de 5 de mayo de 2020 es un buen ejemplo: los kafiles son los tíos de la menor y pretenden su adopción en España, que se les niega por el art. 19 LAI. De haberse constituído la adopción en España, se habrían convertido en padres adoptivos, filiación no reconocida en Marruecos, país en el que tiene además padres biológicos. También lo es un caso anterior de la misma AP de 19 de diciembre de 2017 (ECLI: ES: APV:2017:3805) en el que se aplica el régimen jurídico anterior, y revoca la adopción de una menor kafalada en Marruecos por no haber cumplido con el trámite del art. 177 del CC de oir a la madre biológica. Los solicitantes alegan: que la comisión rogatoria para que la madre de la menor sea oída sobre la adopción podría dar lugar a perjuicios irreparables, en tanto que Marruecos prohíbe la adopción y el juzgado que concedió la «kafala» a favor de los demandantes, de enterarse, podría extinguir de oficio ese derecho.
} 
greso de los Diputados durante su tramitación ${ }^{29}$. La norma se ha vuelto a incluir en la LAI con el mismo texto y en el mismo artículo (ubicación sistemática que el Auto comentado critica) tras reforma operada por Ley $26 / 2015^{30}$, y en este caso no se aceptaron las enmiendas que proponían su supresión ${ }^{31}$. La regla impide la adopción posterior en España si está prohibida por la ley nacional del niño y, por tanto, como ha señalado el Dictamen 3/2016 del FGE, "la limitación contenida en el apartado 4 del art. 19 de la Ley de Adopción Internacional, requiere que el menor conserve su nacionalidad de origen, ya que, si el menor adquiere la nacionalidad española, tal limitación dejaría de ser operativa" ${ }^{32}$. Así lo ha señalado también el TEDH en 2012 en el caso Harroudj contra Francia ${ }^{33}$. Tampoco opera en los casos de niños declarados en desamparo y tutelados por la Entidad pública en España, como también recoge el Derecho francés ${ }^{34}$ y es precisamente a estos casos, a los que se refiere la Exposición de motivos cuando señala que la prohibición tiene alguna matización ${ }^{35}$. Finalmente, como se ha puesto muy oportunamente de relieve ${ }^{36}$, una tercera excepción a la prohibición es la adopción cuando el makfoul haya llegado a la mayoría de edad.

10. Finalmente, se ha planteado en dos recientes resoluciones judiciales, la transformación por los tribunales españoles de una kafala en un acogimiento o en una tutela. En el primer caso procede dicha transformación ${ }^{37}$, pero en el segundo se atribuye a la solicitante la guarda de hecho de su sobrino con funciones tutelares ${ }^{38}$.

\section{La kafala en el Derecho de extranjería y nacionalidad español}

11. Dado que las kafalas estudiadas implican el traslado del niño a España, es oportuno analizar los aspectos de Derecho de extranjería y de nacionalidad, que, en casos como el presente, pueden estar condicionando o "contaminando" los aspectos de Derecho privado. Lo primero que debe advertirse es que el menor debe haber sido autorizado a salir del territorio de su Estado de origen, existiendo al respecto diversas exigencias en la legislación de extranjería de dichos Estados para autorizar la salida ${ }^{39}$. En el Auto estudiado, la AP señala que el Tribunal de Tánger no autorizó ni su desplazamiento a Espa-

${ }^{29}$ En la $n^{\text {o }} 62$ de Izquierda Unida-ICV, la justificación es llamativa: "se intenta dar respuesta a una realidad sociológica relativamente frecuente no solo en Cataluña, sino en Andalucía y en otras comunidades, de familias que marchan a Marruecos a buscar un hijo al que acogen en kafala tras declarar formalmente su conversión al Islam".

${ }^{30}$ Art. 19.4. En el caso de menores cuya ley nacional prohíba o no contemple la adopción se denegará la constitución de la adopción, excepto cuando el menor se encuentre en situación de desamparo y tutelado por la Entidad Pública.

${ }^{31}$ Crítica con esta reforma es E. RODRÍGUEZ PINEAU. "La protección en España de menores cuya ley nacional prohíbe la adopción tras la reforma de la Ley 54/2007, de Adopción internacional” Derecho Privado y Constitución, n 31, 2017, pp. 398-9.

${ }^{32}$ M.J. SÁnchez CAno, “Adopción en España de menores en situación de Kafala y Ley Nacional del Adoptando”, CDT vol. $10, \mathrm{n}^{\mathrm{o}} 2$, octubre 2018, pp. 932-933.

${ }^{33}$ de 4 de octubre de 2012 (TEDH 2012189).

${ }^{34}$ L'adoption d'un mineur étranger ne peut être prononcée si sa loi personnelle prohibe cette institution, sauf si ce mineur est né et réside habituellement en France (art. 370-3 Code civil français).

35 "La imposibilidad de constituir adopciones de menores cuya ley nacional las prohíba, con alguna matización, para evitar la existencia de adopciones claudicantes que atentan gravemente a la seguridad jurídica del menor". El Auto señala que alguna resolución judicial ha interpretado, en otro sentido, esta "matización" sobre la prohibición.

${ }^{36}$ M. GUZMÁN ZAPATER. "Kafala y Derecho español..” op. cit. p. 1040.

${ }^{37}$ En el Auto de la AP de León de 27 de junio de 2019 ya citado, se acuerda la constitución de un acogimiento familiar permanente de una menor kafalada judicialmente; la base jurídica es el art. 34 de la LAI, pero no se trata como un reconocimiento sino como una constitución ex novo de un acogimiento familiar permanente para el que se han solicitado informes a la Entidad Pública de protección de menores. Vid el comentario de M. GUZMÁN ZAPATER, "Kafala y Derecho español.." op. cit.

${ }^{38}$ Se trata del Auto de 11 de junio de 2020 de la AP de Barcelona; ante la demanda presentada una kafil argelina residente en España a la que le han entregado el cuidado de su sobrino a través de una kafala notarial, solicita a los tribunales españoles la privación de la patria potestad de los padres y la posterior constitución una tutela de su sobrino para poder ostentar su representación legal. La Audiencia no considera que los padres, residentes en Argelia, puedan ser privados de la patria potestad y por ello se atribuye a la kafil la guarda de hecho con funciones tutelares prevista en arts. 222-35 a 222-47 del Codi Civil de Catalunya. Esta solución es adecuada, ya que la misma AP había negado anteriormente la constitución de tutelas: Autos de la AP de Barcelona de 12 abril de 2011 (JUR 2011\321814), núm. 116/2011 de 17 mayo (JUR 2011\293829) y de 26 julio de 2011 (JUR 2011\405248).

${ }^{39}$ RODRÍGUEZ VÁzQUEZ, M.A. "Algunos aspectos del Derecho de extranjería en la adopción internacional”, En RODRíGUEZ Benot, A. GonzÁlez Martín, N. Estudios sobre adopción internacional. UNAM México, 2001, p. 256. Las novedades en Marruecos a partir de 2012 las expuse en "Un estudio de caso sobre adoptabilidad...”. Op. cit. 
ña ni que fijara aquí su residencia permanente. Quizá por esa razón los kafiles solicitan su adopción ${ }^{40}$. Contrasta la "prohibición de salida" de Marruecos en este caso, con la autorización de salida del caso resuelto por la misma AP un día después en el que ante una kafala notarial argelina, no solo se permite la salida de Argelia, sino que accede a España con un visado español.

12. Desde la perspectiva del Derecho español de extranjería, no existe ninguna previsión expresa relativa a la kafala, aunque se han aprobado diversas Instrucciones de los Centros directivos competentes al respecto ${ }^{41}$. En la práctica se ha excluído la aplicación del régimen de comunitarios aunque el kafil sea español (como el supuesto del Auto), entendiendo que, dado que la kafala no establece vínculos de filiación, los makfoules no son beneficiarios de reagrupación familiar por no ser estrictamente "descendientes" ${ }^{42}$. Sin embargo, la Sentencia del TJUE de 26 de marzo de $2019^{43}$, considera que si los makfoules están tutelados por kafiles, y llevan una vida familiar efectiva pueden tener el derecho de entrada y residencia como «otro miembro de la familia» de un ciudadano de la Unión ${ }^{44}$. Esta interpretación, consistente con el interés superior del niño y el respeto a su vida familiar, ya fue recomendada por el Defensor del Pueblo al Centro directivo responsable de la inmigración, solicitando que se incluyesen estos supuestos en el ámbito de aplicación del régimen comunitario ${ }^{45}$.

13. Si ninguno de los kafiles es español o ciudadano de la UE, el tratamiento de extranjería depende del tipo de kafala ${ }^{46}$. Si se trata de una kafala judicial de un menor huérfano o de padres desconocidos con tutela dativa, en aplicación del régimen general de extranjería, el kafil deberá solicitar para el makfoul un visado de reagrupación familiar regulado por la Ley de extranjería ${ }^{47}$, para el cual debe aportar una determinada documentación ${ }^{48}$ y reunir unas determinadas condiciones, entre las que destacan los recursos económicos y la vivienda adecuada, condiciones que, si no se cumplen, pueden suponer una denegación de entrada. La jurisprudencia ha ratificado este tratamiento legal reconociendo la expedición de un visado de este tipo en las kafalas judiciales siempre que se demuestre la representación legal, la tutela dativa, y la asignación judicial y no intrafamiliar ${ }^{49}$. En un reciente caso, en que se había negado el

${ }^{40}$ Es justamente lo que sucede en el Auto de la misma AP de 28 de mayo de 2019, en un caso similar de menor declarado en desamparo y kafalado judicialmente. Marruecos autoriza la salida, pero las autoridades españolas no le conceden el visado. Los padres, residentes en Barcelona, 5 años después solicitan la adopción: el menor vive prácticamente desde su nacimiento con los actores en Marruecos, y ante la imposibilidad de ser trasladado a España al estarle vedada la posibilidad de obtención de residencia, solicitan su adopción.

${ }^{41}$ Instrucción- consulares $n^{\text {o }} 404$ de 11 de noviembre de 1996 sobre criterios que rigen la actuación consular en materia de adopción internacional, Instrucción de la DG de Inmigración de 1 de diciembre de 2004, Instrucción de la Dirección General de Inmigraciones de 27 de septiembre de 2007, Instrucción DGI/SGRJ/01/2008 sobre la reagrupación familiar de menores o incapaces sobre los que el reagrupante ostenta la representación legal.

${ }^{42}$ En este sentido sentencias del TSJ de Madrid, 12 septiembre de 2007 (JUR\2009\33365) y TSJ de Andalucía, de 19 junio 2007 (JUR\2008\52873).

${ }^{43}$ ECLI:EU:C:2019:248.

${ }^{44}$ Art. 3, apartado 2, letra a), de la Directiva 2004/38, y 2 bis del RD 240/2007 de Comunitarios. I.E. Lazaro GonzÁLEZ, "Kafala y vida familiar desde el Derecho de extranjería. A propósito de la sentencia del Tribunal de Justicia de la UE (Gran sala) de 29 de marzo de 2019. REEI n 37, 2019, pp. 32-8; M. J. SANCHEZ CANO, "la aplicación de la Directiva 2004/38/CE en supuestos de kafala internacional”. CDT, vol. 12, nº 1, marzo 2020, pp. 713-727; N. MARCHAL ESCALONA. "La kafala, ciudadanía de la unión y los derechos fundamentales del menor: de Estrasburgo a Luxemburgo”. La Ley Unión Europea, nº 71, 2019.

${ }^{45}$ E. ARCE. "La kafala marroquí la legislación de extranjería" Revista de derecho migratorio y extranjería, nº 13, 2006, p. 276.

${ }^{46}$ Sentencias del TSJ de Madrid, de 2 de octubre de 2008 (JUR 2008\27362) y de 9 de julio de 2009 (JUR 2009\431240).

${ }^{47}$ Art. 17. Ley Orgánica 4/2000, de 11 de enero, sobre derechos y libertades de los extranjeros en España y su integración social. (Reformada por LO 8/2000, LO 14/2003, LO 2/2009, LO 10/2011, y RDL 16/2012).

${ }^{48}$ Instrucción de servicio $n^{\circ} 37$ de la Subdirección general de Asuntos de extranjería de 21 de abril de 2009.

${ }^{49}$ Por ello, en general, se han denegado visados en casos de kafalas "judiciales" intrafamiliares: Sentencias del TSJ de Madrid, de 11 de junio de 2008 (JUR 2008\294139), de 11 de septiembre de 2008, (JUR 2009\42129), de 25 febrero de 2010 (JUR 2010`166841), núm. 610/2015 de 8 junio (JUR 2015 181405) y núm. 139/2016 de 18 febrero (JUR 2016\77878). Sentencia del TSJ de Cataluña núm. 635/2014 de 16 julio (JUR 2015\627). Sin embargo, ha habido excepciones en kafalas judiciales intrafamiliares pero con declaración de abandono y tutela dativa: Sentencias del TSJ de Madrid: 16 marzo de 2006, (JUR\2006\14892) y dos de 2008 (de 3 de abril -JUR\2008\189480- y 2 octubre -JUR\2009\27362-). E incluso ha habido excepciones en kafalas notariales homologadas judicialmente: TSJ de Madrid, de 23 mayo de 2005 (JUR 2006\214863); TSJ de Madrid, 14 marzo de 2008 (JUR 2008\217100); Sentencia del TSJ de Andalucía de 23 de mayo de 2019 ya citada. 
visado por no aportar el libro de familia de la menor, cuando en Marruecos los hijos de madre soltera no tienen libro de familia, el TSJ de Madrid ha eximido de este requisito ${ }^{50}$.

14. En caso de kafalas notariales, según la Instrucción de la Dirección General de Migraciones de 27 de septiembre de 2007, se entiende que el "kafil" no puede ser considerado «representante legal» del menor extranjero, y se propone que el visado se tramite por el procedimiento que regula el desplazamiento temporal de menores extranjeros por motivos de estudios o humanitarios (arts. 187 y 188 del Reglamento de extranjería $\left.{ }^{51}\right)$. La jurisprudencia ha confirmado este tratamiento en virtud del cual no procede en estos supuestos el visado por reagrupación familiar ${ }^{52}$, ni la posterior autorización de residencia ${ }^{53}$, aunque se advierten algunas excepciones ${ }^{54}$. En los casos en los que el menor había entrado ya en España se ha concedido en alguna ocasión la "exención de visado" 55 y en otros ha sido denegada ${ }^{56}$. Ha habido algún otro caso en el que la solicitud "peculiar" ha sido de un visado de turismo, para estancia corta de 7 días que se ha denegado ${ }^{57}$. La dificultad de articular los cauces para regular la entrada y residencia legal de estos menores, respecto de los que se ha constituído una kafala notarial, se ha dado también en otros países de Europa, como pone de relieve la sentencia ya citada del TEDH de 16 de diciembre de 2014. Debe tenerse presente que si el kafil no es el representante legal del menor, y éste permanece en el país de origen, se plantean serios problemas de todo tipo relacionados con la representación legal y la seguridad jurídica del menor. Es evidente, de nuevo, que el carácter de representación legal, y su prueba, es la clave jurídica de muchos de estos casos.

15. En relación al Derecho de nacionalidad, la kafala no atribuye ex lege la nacionalidad española al kafil si el makfoul es español, toda vez que no puede calificarse como adopción (artículo 19.1 del Código Civil). Tampoco es posible que el kafil ejerza el derecho de opción a la nacionalidad española en favor del makfoul, como ha señalado la DGRN ${ }^{58}$. Sin embargo, podrá solicitarse la nacionalidad del makfoul tras un año de residencia legal en España según lo previsto en el artículo 22 del Código Civil, si bien en algún caso no se ha permitido al kafil que la solicite en su nombre por negarle su carácter de representante legal ${ }^{59}$. La obtención de la nacionalidad española puede ser muy relevante en casos de posterior ofrecimiento para una adopción ante juez español, como actualmente permite la legislación española, tal y como ha señalado el FGE en su Dictamen 3/2016.

5031 de mayo de 2019 (ECLI:ES: TSJM: 2019:8516).

${ }^{51}$ Real Decreto 557/2011, de 20 de abril, por el que se aprueba el Reglamento de la Ley Orgánica 4/2000, sobre derechos y libertades de los extranjeros en España y su integración social, tras su reforma por Ley Orgánica 2/2009. (BOE de 18 de junio de 2011).

${ }^{52}$ Sentencia del Tribunal Supremo de 9 diciembre 2011. (JUR 2011 433222), y sentencias de otros tribunales: TSJ de La Rioja de 21 febrero de 2005 (JUR 2006\291265); TSJ de Madrid de 20 septiembre de 2006 (JUR 2008\54022); de 11 octubre de 2007 (JUR 2008\47910); de 5 de junio de 2008 (JUR 2008\294252); de 10 julio de 2008 (JUR 2008\315217); de 16 de junio de 2009 (JUR 2009\408525); de 11 febrero de 2010 (JUR 2010\168494); de 25 junio de 2010 (RJCA\2010\690); de 20 mayo de 2011 (JUR 2011 280497). TSJ de Andalucía de 14 enero de 2005 (JUR 2007\51157), y de 30 noviembre de 2007 (JUR 2008\304658); TSJ País Vasco de 23 de septiembre de 2008 (JUR 2009\3819), del TSJ de Castilla-La Mancha 8 noviembre de 2010 (JUR 2011 42243 ); TSJ de Cataluña de 30 diciembre de 2009 (JUR 2010\159627); TSJ de Madrid no 659/2016 de 26 de septiembre de 2016 (JUR 2016\240895); TSJ de Cataluña núm. 86/2016 de 18 febrero (JUR 2016\130950); TSJ del País Vasco, núm. 147/2015 de 3 marzo. (JUR 2015\133783); TSJ de Cataluña de núm. 44/2015 de 22 enero. (JUR 2015\153408).

${ }^{53}$ Sentencias de la Audiencia Nacional de 2 febrero 2011 (JUR\2011\68466), del TSJ de Castilla-La Mancha de 17 marzo de 2011 (JUR 2011\167479), del TSJ de Cataluña de 21 octubre de 2010 (JUR 2011\151541), del TSJ de Madrid de 18 marzo de 2009 (JUR 2010\270275).

${ }^{54}$ Sentencias del TSJ de Cataluña de 15 julio de 2011 (JUR 2011\323594) y del TSJ de Madrid núm. 643/2016 de 21 septiembre. (JUR 2016\241572).

${ }^{55}$ Sentencias del TSJ de Andalucía de 14 de septiembre de 2004 (JUR 2006\94014) y de 21 octubre 2005 (JUR 2006\71643).

${ }^{56}$ Sentencias del TSJ de Andalucía de 20 julio de 2009 (JUR 2010\6041), del TSJ de Aragón de 21 junio de 2005(JUR 2006\137207) y del TSJ de Madrid de 11 de abril de 2019 ya citada.

57 TSJ de Madrid de 11 de abril de 2019, ya citada.

${ }^{58}$ Resoluciones de 1 de febrero de 1996, de 21 de marzo de 2006 (JUR 2007\111879), núm. 4/2011 de 29 marzo. (JUR 2012 \86539), núm. 25/2012 de 29 octubre (JUR 2013\322447), núm. 106/2013 de 15 noviembre. (JUR 2014\214471(; núm. 11/2011 de 6 septiembre (JUR 2012\198189).

${ }^{59}$ Resolución núm. 62/2015 de 12 junio ya citada. 


\section{Consideraciones finales}

16. La prohibición de constituir una adopción en España tras una kafala en el país de origen del niño incluída en art. 19.4 de la LAI en 2015, y aplicada adecuada y justificadamente por la AP de Barcelona, al igual que prohibiciones similares en otros Derechos europeos, ha supuesto que esta figura del Derecho de familia islámico haya dejado de utilizarse como alternativa a la adopción internacional por parte de familias españolas y europeas. Sin embargo, la inexistencia de una adecuada regulación en la normativa de extranjería, española, pero también de algunos países de origen, está abocando a kafiles de origen islámico residentes en Europa, como los del Auto analizado, a acudir a la adopción como alternativa para que el niño pueda entrar y residir en España; así sucedió también en el caso Chbihi Loudoudi y otros contra Bélgica resuelto por el TEDH en 2014. La solución propuesta por la Sentencia del TJUE de 26 de marzo de 2019 puede ser adecuada si el kafil ha adquirido ya la nacionalidad española, pero en caso contrario, el análisis de este Auto y otros muchos, pone de relieve una necesaria reforma de nuestra legislación de extranjería que garantice a los menores extranjeros que han sido objeto de esta medida de protección, su derecho a vivir en familia como parte esencial de su derecho a que su interés superior sea la consideración primordial en todas las decisiones que les afecten. 